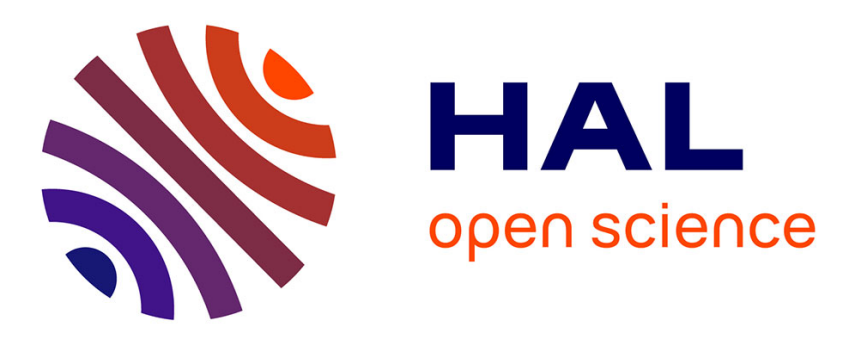

\title{
Fault Detection, Isolation and Control Reconfiguration of Three-Phase PMSM Drives
}

\author{
Fabien Meinguet, Xavier Kestelyn, Eric Semail, Johan Gyselinck
}

\section{To cite this version:}

Fabien Meinguet, Xavier Kestelyn, Eric Semail, Johan Gyselinck. Fault Detection, Isolation and Control Reconfiguration of Three-Phase PMSM Drives. 2011 IEEE International Symposium on Industrial Electronics (ISIE), Jun 2011, Poland. pp.2091-2096, 10.1109/ISIE.2011.5984483 . hal00794388

\section{HAL Id: hal-00794388 \\ https://hal.science/hal-00794388}

Submitted on 25 Feb 2013

HAL is a multi-disciplinary open access archive for the deposit and dissemination of scientific research documents, whether they are published or not. The documents may come from teaching and research institutions in France or abroad, or from public or private research centers.
L'archive ouverte pluridisciplinaire HAL, est destinée au dépôt et à la diffusion de documents scientifiques de niveau recherche, publiés ou non, émanant des établissements d'enseignement et de recherche français ou étrangers, des laboratoires publics ou privés. 


\title{
Fault Detection, Isolation and Control Reconfiguration of Three-Phase PMSM Drives
}

\author{
Fabien Meinguet*, Xavier Kestelyn ${ }^{\S}$, Eric Semail ${ }^{\S}$ and Johan Gyselinck* \\ *BEAMS Department, Université Libre de Bruxelles (ULB), Brussels, Belgium \\ e-mail: Fabien.Meinguet@ulb.ac.be \\ ${ }^{\S}$ L2EP, Arts et Métiers ParisTech, Lille, France
}

\begin{abstract}
This paper deals with on-line software fault detection and isolation method for a drive composed of a fourleg inverter and a three-phase permanent magnet synchronous machine. The considered faults are single-phase open-circuit and current sensor outage. The method is based on the monitoring of the $a b c$ currents with phase-locked loops and the 'CUSUM' algorithm for the decision system. The impact of the considered faults is examined: first, in case there is no modification of the control and then in case a control reconfiguration is performed taking into account the fault diagnosis. Closed-loop operation is performed before, during and after the fault. Experimental results show that the latter case allows maintaining the drive in safe operation.
\end{abstract}

\section{INTRODUCTION}

The need for reliability and continuous operation has lead all over the years to the development of fault-tolerant electrical drives for various industrial purposes and for transport applications [1], [2]. Although permanent magnet synchronous machines (PMSM) are not inherently fault tolerant, especially to short-circuit in the windings, their power density and absence of maintenance make them a good trade-off in applications where weight and volume are particularly important.

Fault detection can be generally performed with hardware devices and/or software methods. Hardware devices have to be used when software methods are unsuitable, i.e. when the characteristic time of the fault is much smaller than the sampling period. An example is a short-circuited IGBT that can be managed with gate drive protection. Hardware devices are generally costly and complex but can provide a fast and reliable detection, while software requires only computation time but can be slower.

Survey papers dedicated to machine faults describe very well the different faults and various software methods to detect them [3]-[5]. Current-based methods are obviously attractive for drives since the currents are measured for the control and protections anyway. Hence, a current measurement-based diagnostic can be implemented without additional cost.

Inverter faults and fault-tolerant three-phase topologies are investigated in [6]. Redundancy is adopted to cope with switch faults and the authors suggest to access the neutral point of the machine or to supply each phase individually to keep the motor in operation after the fault mitigation. Considering PMSM drives, the neutral accessibility may be an issue since most of the commercial PMSMs have no neutral connection. However, fault-tolerance should be taken into account from the beginning when designing a fault-tolerant drive. The neutral connection can cause different problems that can be solved with an appropriate PMSM design. First, the electromotive force (emf) zero-sequence component should be as low as possible. It prevents the flow of a current zero-sequence component that creates torque ripple, unless a complex current control is implemented [7]. Secondly, the zero-sequence inductance can be much lower than the $d q$-axis inductance, leading to a high current ripple and losses. This can be avoided by choosing a design with no mutual inductance, for instance with a fractional-slot winding and non-overlapping coils [8].

The authors of [9] propose the idea of detecting mechanical sensor faults by comparing the output of the sensor with the estimation of a sensorless algorithm. They also suggest detecting dc-link voltage sensor fault based on a power balance equation. Moreover, a test at standstill assessing the condition of the current sensors is detailed. In case of current sensor fault, observers are used to reconstruct the missing data.

Current sensor fault detection and isolation (FDI) is studied in [10]-[13] with two different approaches: in [10], a modelbased fault detection and isolation is performed, whereas [11]-[13] uses a signal-based approach. A shortcoming of these methods is that they all perform the fault detection and isolation with an open-loop control, except in [13] where the fault is detected but not isolated. Generally, modelbased methods are sensitive to parameter variations and/or uncertainties, while signal-based methods present a lack of performance with a closed-loop controller.

Beyond the ease of repair brought by the FDI, it makes fault-tolerant control (FTC) possible since the controller knows which component is faulty and can adapt the control strategy accordingly. For example, FTC for induction motor drives is presented in [14], where an architecture that changes the control algorithm in function of the available sensors is presented. A different way to achieve FTC is to take benefit of the additional degrees of freedom in case a fault tolerant topology is used. For example, it is possible to reconfigure the control to drive the machine with two phases and the neutral point [15], [16].

In this paper, we consider a fault-tolerant topology where the inverter has one additional leg. By connecting this leg continuously to the neutral point of the machine, we show how the effect of a fault is reduced. This is particularly important since the software FDI method needs some time to be executed and the system needs then to withstand the fault while waiting for a control reconfiguration.

The proposed FDI method is based on a phase-locked loop (PLL) [12], [17] and the CUSUM algorithm for the decision 


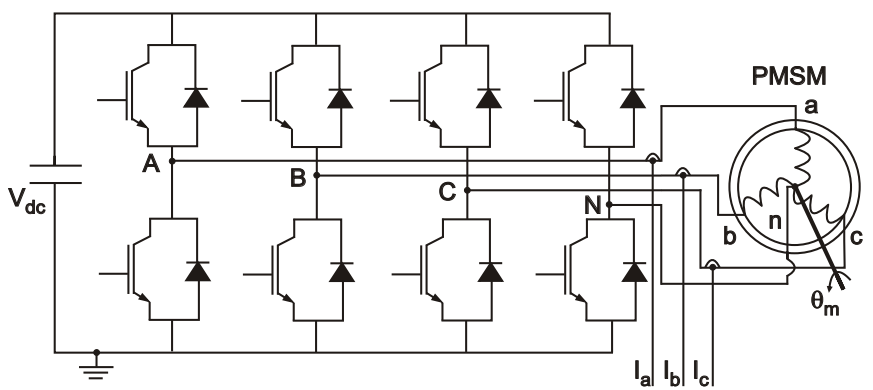

Figure 1. Drive topology: a four-leg VSI supplying a three-phase PMSM.

system [18]. PLL allows tracking the frequency of the current signals, which deviates from the electrical pulsation for the studied faults. The 'CUSUM' algorithm allows taking a decision whether there is a fault or not. From the fault diagnosis the control reconfiguration is then activated. The decision to stop supplying the faulty phase is taken systematically, whatever the fault. The advantages of this method are that: it performs the FDI with a closed-loop controller; it is robust to parameter variations and uncertainties; it allows the detection and isolation of two different faults with similar properties (single-phase open circuit and current sensor outage).

\section{DRIVE Model}

In this section we describe the drive model composed of a three-phase star-connected PMSM and a four-leg inverter as shown in Fig. 1. The three phase-currents, the dc-link voltage and the mechanical position are measured.

\section{A. PMSM model with connected neutral point}

In what follows, we consider that effects of saliency and saturation are negligible and the emf harmonic content is negligible beyond the third harmonic component.

1) Natural abc model: the voltage equations expressed in the $a b c$ reference frame are given by:

$$
\left[\begin{array}{l}
V_{a}-V_{n} \\
V_{b}-V_{n} \\
V_{c}-V_{n}
\end{array}\right]=R_{s}\left[\begin{array}{c}
I_{a} \\
I_{b} \\
I_{c}
\end{array}\right]+\left[\begin{array}{ccc}
L & M & M \\
M & L & M \\
M & M & L
\end{array}\right] \frac{d}{d t}\left[\begin{array}{c}
I_{a} \\
I_{b} \\
I_{c}
\end{array}\right]+\left[\begin{array}{c}
E_{a} \\
E_{b} \\
E_{c}
\end{array}\right]
$$

where $R_{s}$ is the stator resistance, $L$ and $M$ are the stator phase self and mutual inductances, $V_{x}, I_{x}, E_{x}$ are the $x$ phase voltage with respect to a common reference, the $x$-phase current and the emf induced by the magnets in the $x$-phase respectively $(x \in\{a, b, c\})$ and $V_{n}$ is the voltage between the neutral point of the machine and the common reference. The neutral current $I_{n}$ is given by:

$$
I_{n}=-\left(I_{a}+I_{b}+I_{c}\right) .
$$

2) Synchronous $d q 0$ model: the model of the machine expressed in the $d q 0$ synchronous reference frame is obtained by applying the Park transformation defined by:

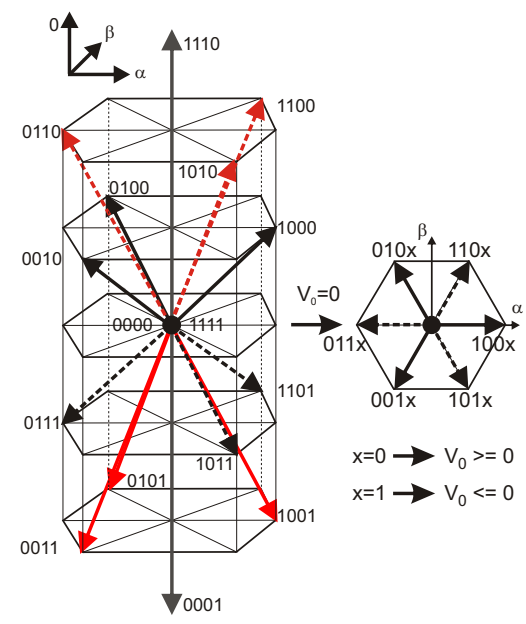

Figure 2. Four-leg VSI: the 16 voltage space vectors and their projection on a $V_{\alpha \beta}$ plane.

$$
\begin{array}{r}
{\left[X_{d q 0}\right]=[P]\left[X_{a b c}\right] ;\left[X_{a b c}\right]=[P]^{-1}\left[X_{d q 0}\right]} \\
{[P]=\frac{2}{3}[R][C] ;[P]^{-1}=[C]^{t}[R]^{t}} \\
{[R]=\left[\begin{array}{ccc}
\cos \theta_{e} & \sin \theta_{e} & 0 \\
-\sin \theta_{e} & \cos \theta_{e} & 0 \\
0 & 0 & 1
\end{array}\right] ;[C]=\left[\begin{array}{ccc}
1 & -\frac{1}{2} & -\frac{1}{2} \\
0 & \frac{\sqrt{3}}{2} & -\frac{\sqrt{3}}{2} \\
\frac{1}{\sqrt{2}} & \frac{1}{\sqrt{2}} & \frac{1}{\sqrt{2}}
\end{array}\right]}
\end{array}
$$

where $\theta_{e}$ is the electrical position of the rotor. Applying the transformation (3) to the natural system (1) gives:

$$
\begin{gathered}
{\left[\begin{array}{l}
V_{d} \\
V_{q} \\
V_{0}
\end{array}\right]=R_{s}\left[\begin{array}{c}
I_{d} \\
I_{q} \\
I_{0}
\end{array}\right]+} \\
{\left[\begin{array}{ccc}
L_{d q} & 0 & 0 \\
0 & L_{d q} & 0 \\
0 & 0 & L_{0}
\end{array}\right] \frac{d}{d t}\left[\begin{array}{c}
I_{d} \\
I_{q} \\
I_{0}
\end{array}\right]+\omega_{e}\left[\begin{array}{c}
-L_{d q} I_{q} \\
L_{d q} I_{d}+\psi_{M, 1} \\
e_{M, 3}\left(\theta_{e}\right)
\end{array}\right]} \\
L_{d q}=L-M \quad ; \quad L_{0}=L+2 M \quad\left(-\frac{1}{2} L \leq M \leq 0\right)
\end{gathered}
$$

where $\omega_{e}$ is the electrical pulsation, $\psi_{M, 1}$ is the amplitude of the magnet fundamental linkage flux and $e_{M, 3}\left(\theta_{e}\right)$ is the emf third harmonic component for each electrical radian, which a sinusoidal function of $3 \theta_{e}$.

The electromagnetic torque expressed in the $d q 0$ reference frame is equal to:

$$
T_{e m}=\frac{3}{2} P\left(\psi_{M, 1} I_{q}+e_{M, 3}\left(\theta_{e}\right) I_{0}\right)
$$

where $P$ is the number of pole pairs.

Parameters of the machine used for the tests are: $R_{s}=$ $1.39 \Omega, L_{d q}=11.4 \mathrm{mH}, L_{0}=4.9 \mathrm{mH}, \psi_{M, 1}=1.05 \mathrm{Vs} / \mathrm{rad}$, $\frac{e_{M, 3}}{\psi_{M, 1}}=0.06, P=3$. Ratings are: $\Omega_{m}=2000 \mathrm{rpm}$, $P \stackrel{P}{=} 2.59 \mathrm{~kW}, I_{\text {nom }}=5.7 \mathrm{~A}$. As the emf third harmonic component is much smaller than the fundamental component for the considered machine, the zero-sequence component contribution to the electromagnetic torque (8) will be neglected in what follows. 


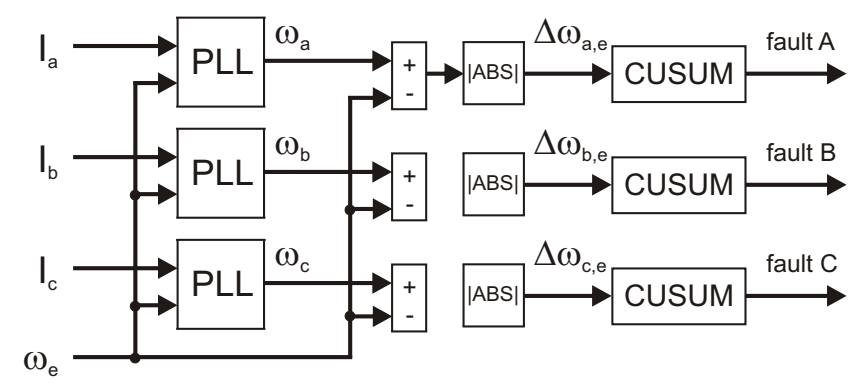

Figure 3. FDI method: monitoring of each phase-current with a PLL and comparison with the motor pulsation. Decision is taken by the CUSUM algorithm.

\section{B. Four-leg inverter model}

A four-leg inverter possesses 4 degrees of freedom, i.e. the upper or lower switch 'on' or 'off' state of each leg [20]. Fig. 2 shows the $2^{4}$ voltage space vectors in the $\alpha \beta 0$ stator reference frame. The four numbers near the vector arrows indicate the state of the $\mathrm{ABCN}$ legs respectively, ' 1 ' meaning that the upper switch is 'on' and ' 0 ' that the bottom switch is 'on'. There are 2 zero vectors, 2 vectors having only a zero sequence component (equal to $\pm \sqrt{2} V_{d c}$ ) and 12 vectors split up equitably into 4 different zero-sequence planes (with $V_{0}$ equal to $\sqrt{2} V_{d c}$ times $-\frac{2}{3},-\frac{1}{3}, \frac{1}{3}$ and $\frac{2}{3}$ respectively). The common factor $\sqrt{2}$ is due to the transformation matrix that is used. It is interesting to note that the commutation of the fourth leg only affects the zero-sequence voltage component and that the projections of the VSVs onto the $\alpha \beta$ plane coincide with the VSVs of the classic three-leg inverter.

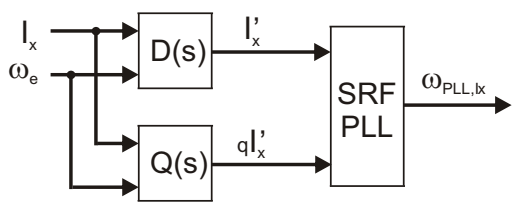

Figure 4. Signal frequency estimation based on an adaptive filtering stage and a synchronous reference frame phase locked-loop.

\section{Fault Detection and Isolation Method}

The proposed FDI method is shown in Fig. 3. The three phase-currents are measured and monitored with modified PLLs. The output of the PLL is the frequency of the signal that is compared to the actual electrical pulsation. The absolute value of the error is then taken as input of the CUSUM algorithm.

\section{A. Phase-locked loop}

Various types of PLL have been proposed in the literature. A PLL expressed in the synchronous reference frame (SRF) has been implemented [17]. An additional adaptive filtering stage has been added at the input of the PLL, as shown in Fig. 4. It consists of a structure called second order generalized integrator-based quadrature signals generator (SOGIGSQ) [19]. Its role is to eliminate harmonics and to generate a quadrature signal needed by the SRF PLL. The $D$ filter transfer function is equal to:
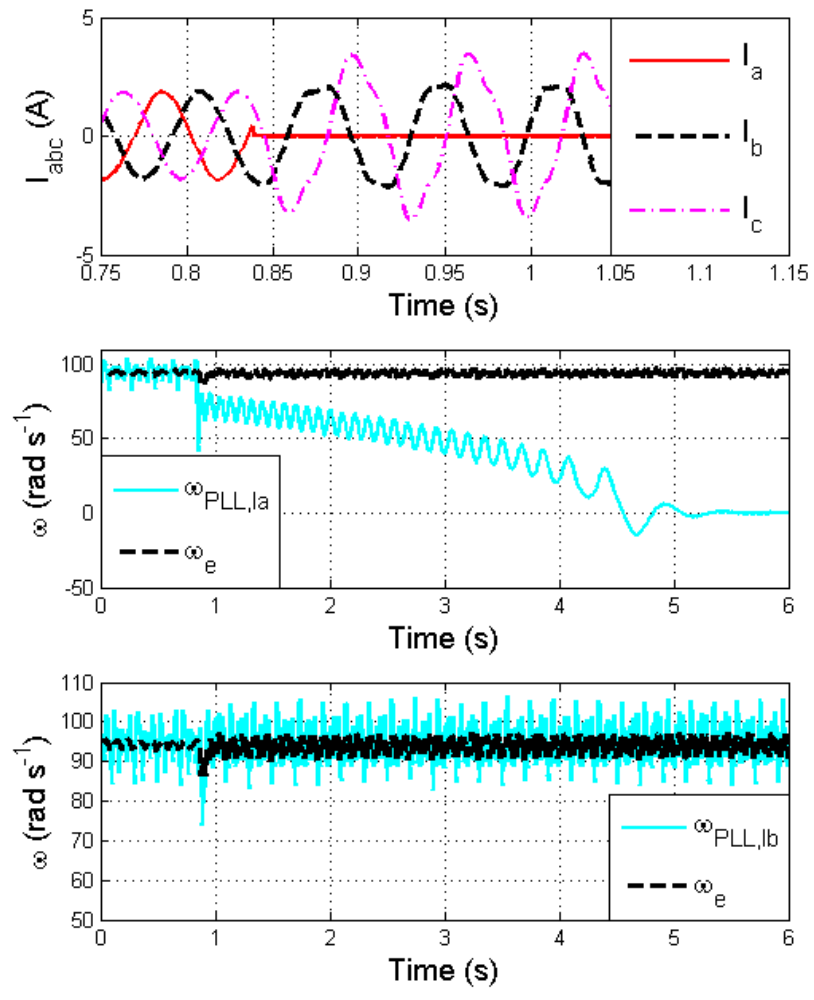

Figure 5. PLL-based frequency monitoring of the phase-currents in case of single-phase open-circuit fault. From top to bottom: $a b c$ phase-currents; $I_{a}$ frequency estimation compared to $\omega_{e} ; I_{b}$ frequency estimation compared to $\omega_{e}$.

$$
D(s)=\frac{X^{\prime}(s)}{X(s)}=\frac{k \omega_{e} s}{s^{2}+k \omega_{e} s+\omega_{e}^{2}}
$$

where $X^{\prime}(s)$ is the filter output, $k$ a damping factor, $s$ the Laplace variable and $\omega_{e}$, the electrical pulsation, is the resonant frequency of the filter.

The quadrature signal generator is a filter of which the transfer function $Q(s)$ is:

$$
Q(s)=\frac{q X^{\prime}(s)}{X(s)}=\frac{k \omega_{e}^{2}}{s^{2}+k \omega_{e} s+\omega_{e}^{2}} .
$$

An example is shown in Fig. 5. A fault on the $a$-phase has been performed at the time $t=0.84 \mathrm{~s}$. When the fault occurs, the signal $\omega_{P L L, I a}$ drops, but not immediately to zero, while the value of the signal $\omega_{P L L, I b}$ remains equal to the electrical pulsation. After several seconds, the frequency estimation reaches zero.

\section{B. CUSUM Algorithm}

A theoretical background of the CUSUM algorithm ('CUMulative SUM') can be found in [18]. This algorithm acts like an integrator that allows detecting variations in signal properties, such as the mean value. The difference of pulsation between the input signal and the electrical pulsation is thus the input of the CUSUM algorithm. 


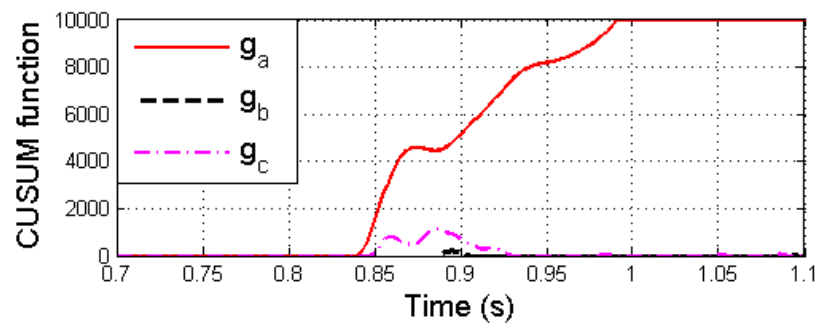

Figure 6. $a b c$ CUSUM functions in case of single-phase open-circuit fault.

In its simplified version, the algorithm consists in computing a function $g$ at each sample time $k$ :

$$
g(k)=\max \left(0, g(k-1)+\left(\left(\Delta \omega_{x, e}(k)-\frac{\mu_{0}+\mu_{1}}{2}\right)\right)\right.
$$

where $\mu_{0}$ and $\mu_{1}$ are the mean value of the signal before and after the fault and $\Delta \omega_{x, e}(k)$ is the input of the CUSUM algorithm (cfr Fig 3). It can be interpreted as follows: before the fault the average value of $\Delta \omega_{x, e}(k)-\frac{\mu_{0}+\mu_{1}}{2}=\frac{\mu_{0}-\mu_{1}}{2}$ will be negative as $\mu_{1}$ is greater than $\mu_{0}=0$ and $g$ will be maintained to zero. After the fault the term becomes positive and $g$ begins to increase with a slope equal to $\frac{\Delta g}{\Delta k}=\frac{\mu_{1}-\mu_{0}}{2}$. When $g$ will reach a user-chosen threshold $h$, the system will set up a flag error. The value of $\mu_{0}=0$ is straightforward and the theory would impose a dynamic value of $\mu_{1}=\omega_{e}$, what is not convenient. Instead, a constant value can be chosen. A value of $h$ can be roughly calculated as a function of an imposed detection time $\Delta t_{\text {detection }}$ and the minimum speed at which the drive should operate $\omega_{e, \min }$ :

$$
h=\Delta t_{\text {detection }} \frac{\omega_{e, \min }-\frac{\mu_{0}+\mu_{1}}{2}}{t_{s}}
$$

where $t_{s}$ is the sampling time.

For, $\mu_{1}=20 \mathrm{rads}^{-1}, \mu_{0}=0 \mathrm{rads}^{-1}, \Delta t_{\text {detection }}=0.2 \mathrm{~s}$, $t_{s}=20 \mu \mathrm{s}$ and $\omega_{e}=20 \mathrm{rads}^{-1}$, it gives $h=10000$. It has to be noted that this relation is only true for a given speed, but according to (12), the detection time will theoretically decreases when the speed increases. On the other hand, it is difficult to tune the PLL on the whole speed range and for different signal amplitudes, what can cause a long transient before the estimation reaches zero (see Fig. 5). Hence, this transient increases the detection time.

Fig. 6 shows the $a b c$ CUSUM functions for the test presented in Fig. 5, i.e. an open-circuit fault in the $a$ phase occurring at time $t=0.84 \mathrm{~s}$. Test parameters are those mentioned above. The $a$-phase CUSUM function reaches the threshold $h$ at time $t=0.99 \mathrm{~s}$, i.e. $0.15 \mathrm{~s}$ after that fault has occurred.

\section{CONTROL STRATEGY}

\section{A. Normal operation}

A scheme of the voltage control with PI controllers in the $d q 0$ reference frame is shown in Fig. 7. The electromagnetic torque reference $T_{e m}^{*}$ is received directly from the user or from a speed controller. The $d q 0$ current references are

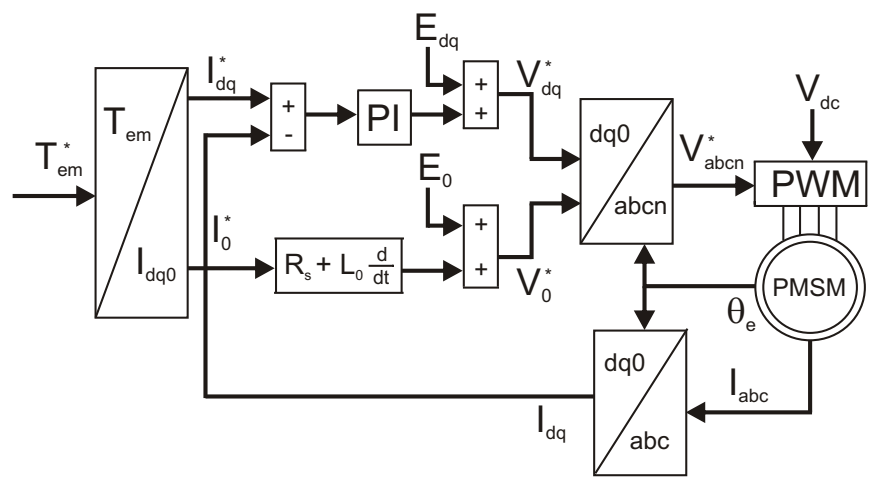

Figure 7. Scheme of the PI voltage control in the $d q 0$ reference frame.

calculated from (8). A compensation of the emf $\left(E_{d q}\right.$ and $\left.E_{0}\right)$ is performed. Simple PI controllers are used for driving the $d$ - and $q$-axis currents.

The algorithm to calculate the duty cycles $\delta$ is given in [21]:

$$
\delta_{x}=\frac{V_{x}^{*}}{V_{d c}} \quad ; \quad \delta_{n}=\frac{V_{n}^{*}}{V_{d c}}
$$

where

$$
\begin{aligned}
& V_{x}{ }^{*}= \\
& V_{x n}{ }^{*}+V_{n}{ }^{*} \\
& V_{n}{ }^{*}=\operatorname{mid}\left(-\frac{V_{\max }}{2},-\frac{V_{\min }}{2},-\frac{V_{\max }+V_{\min }}{2}\right)
\end{aligned}
$$

mid is the function selecting the intermediate value and

$$
\begin{aligned}
& V_{\max }=\max \left(V_{a n}^{*}, V_{b n}^{*}, V_{c n}^{*}\right) \\
& V_{\min }=\min \left(V_{a n}^{*}, V_{b n}^{*}, V_{c n}^{*}\right)
\end{aligned}
$$

\section{B. Control for the post-fault operation}

When a fault occurs in one of the three phases, the decision to stop supplying this phase is taken systematically. The machine will then be driven with two phases and the neutral. According to [15] and [16], keeping constant the $d$ - and $q$-axis current references is possible if the zero-sequence current is equal to:

$$
I_{0, \text { fault }}{ }^{*}=\sqrt{2}\left(I_{q}{ }^{*} \sin \left(\theta_{e}-k \frac{2 \pi}{3}\right)-I_{d}{ }^{*} \cos \left(\theta_{e}-k \frac{2 \pi}{3}\right)\right)
$$

where $k=\{0,1,2\}$ in case of fault in phase $a, b$ or $c$ respectively. Open-loop control of the zero-sequence control will then require a zero-sequence voltage reference equal to:

$$
V_{0, \text { fault }}^{*}=R_{s} I_{0, \text { fault }}^{*}+L_{0} \frac{d}{d t} I_{0, \text { fault }}^{*}
$$

\section{IMPACT OF FAULTS Without CONTROL RECONFIGURATION}

The impact of the fault can be quantified with different indices such as the torque ripple, the current increase in the remaining phases and the speed/torque deviation from their reference.

\section{A. Single-Phase Open-Circuit Fault}

Events leading to a single-phase open-circuit fault are: power electronics fault (after a short-circuit mitigation or gate drive fault) or mechanical fault (broken wire, unscrewed 


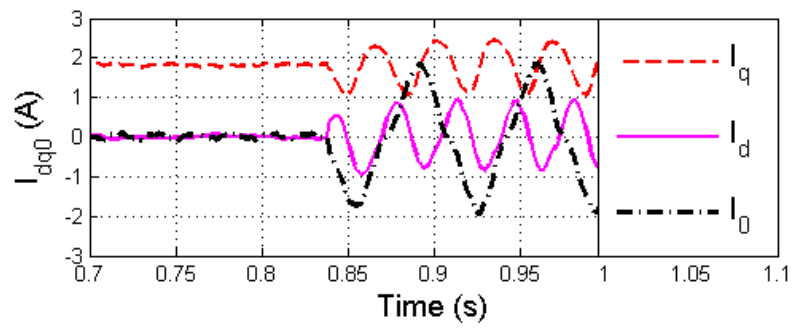

Figure 8. Currents expressed in the rotating reference frame in case of single-phase open-circuit fault.
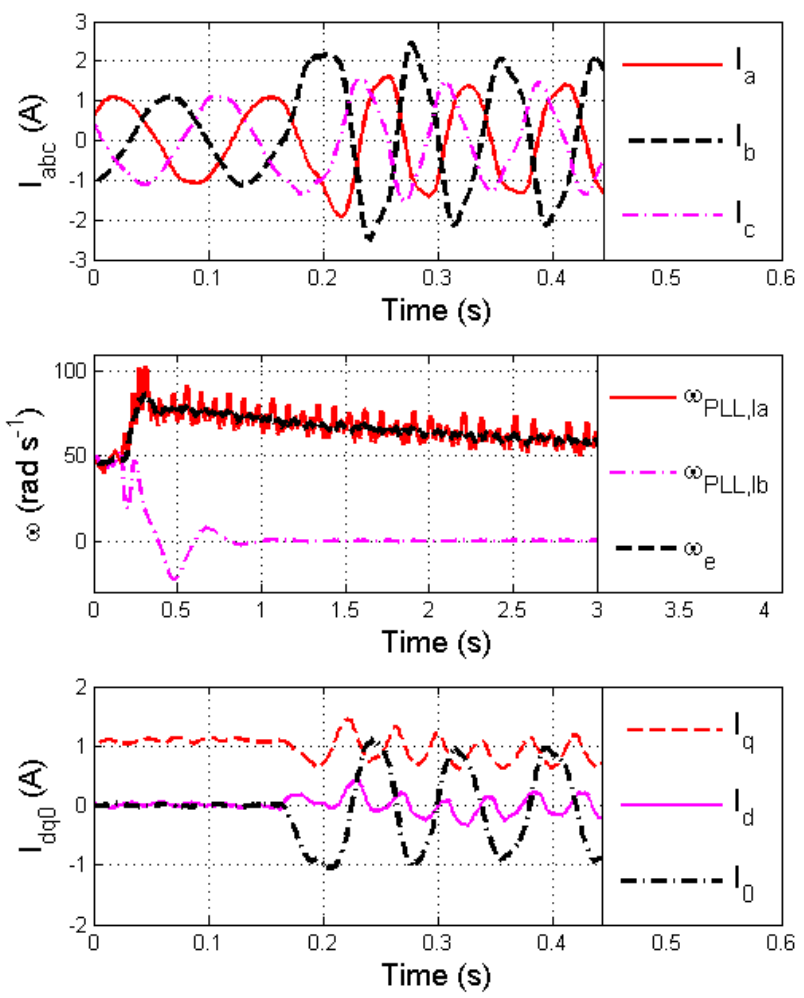

Figure 9. $b$-phase current sensor fault. From top to bottom: real $a b c$ phasecurrents; $I_{a}$ and $I_{b}$ frequency estimation compared to $\omega_{e} ; d q 0$-axis currents seen from the controller.

connector). Response of the classic three-phase drive has been studied in [22]. Torque is pulsating and current increases in the two remaining phases, both amplitudes depending on the current controller. The speed keeps its average value and the speed ripple depends on the inertia of the system.

Fig. 8 shows the $I_{d q 0}$ currents for the considered fault and the proposed control and topology. The peak-to-peak torque ripple is reduced with a factor 3 compared to the classic three-phase system. This is due to the neutral connection and because the neutral current is free to flow (open-loop voltage control of the zero-sequence component).

\section{B. Current Sensor Fault}

Test results with a $b$-phase current sensor fault at time $t=0.16 s$ is presented in Fig. 9. The real $a b c$ phase-currents are shown on the top. The increase of the currents is due to
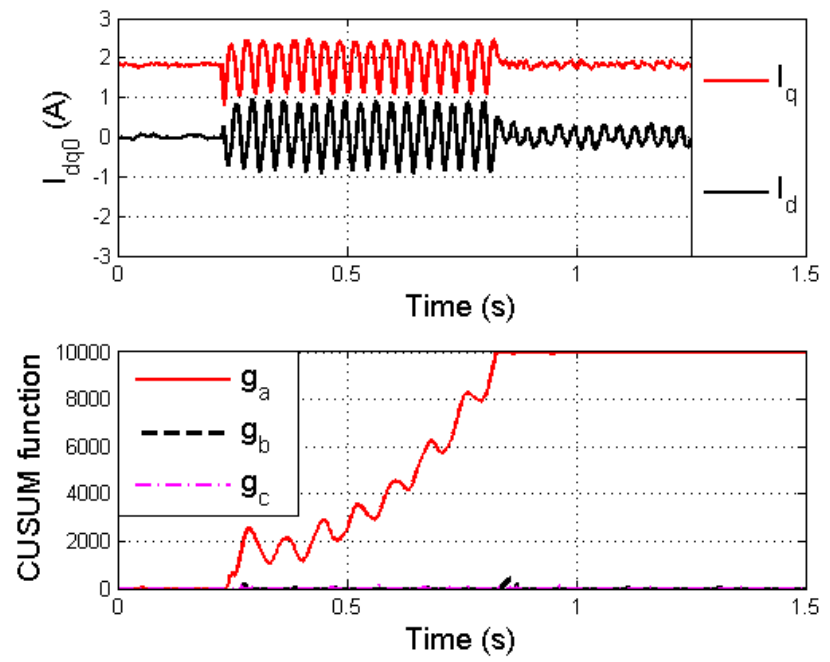

Figure 10. Response of the drive in case of single-phase open-circuit fault (a-phase). Fault is detected, isolated and the control is reconfigured when the $a$ CUSUM function reaches the threshold.

the controllers, which have to impose their reference based on the $a$ - and $c$-phase current measurements only. However, the real $b$-phase current is different from zero, what gives an electromagnetic torque higher than expected. The motor speed increases until almost twice the initial speed (middle figure). It has to be noted that the $a$-phase frequency estimation follows the speed measurements very well whereas the $b$-phase frequency estimation reaches zero as expected. The speed controller will then decrease the torque reference to restore the steady-state. This explains why the $q$-axis current seen from the controller slowly decreases (bottom figure).

\section{FDI AND CONTROL RECONFIGURATION}

\section{A. Single-Phase Open-Circuit Fault}

Fig. 10 shows the test results where a single-phase opencircuit fault occurs at time $t=0.23 \mathrm{~s}$ in the $a$-phase. The $a$ CUSUM function reaches the threshold at time $t=0.83 \mathrm{~s}$. Operating conditions are: $\Omega_{m}=300 \mathrm{rpm}, T_{e m} \approx 5 \mathrm{Nm}$. We can observe that the control reconfiguration reduces the $q$-axis current ripple to nearly zero.

\section{B. Current Sensor Fault}

Fig. 11 shows the test results where a current sensor fault occurs at time $t=0.31 s$ in the $b$-phase. The $b$ CUSUM function reaches the threshold at time $t=0.42 \mathrm{~s}$. Operating conditions are: $\Omega_{m}=150 \mathrm{rpm}, T_{e m} \approx 2.8 \mathrm{Nm}$. We can observe that the control reconfiguration reduces again the $q$ axis current ripple to nearly zero. A comparison with the single-phase open-circuit fault shows that: in case there is no open-circuit fault, the current is still able to flow in the machine and is then not exactly equal to zero (top figure). The speed still increase when the fault occurs. However, the electromagnetic torque is restored with the control reconfiguration and the speed controller must not compensate the error anymore. Another main difference is that the detection time is much lower for the second test. This is due to the PLL transient response that takes more time for higher speeds. 

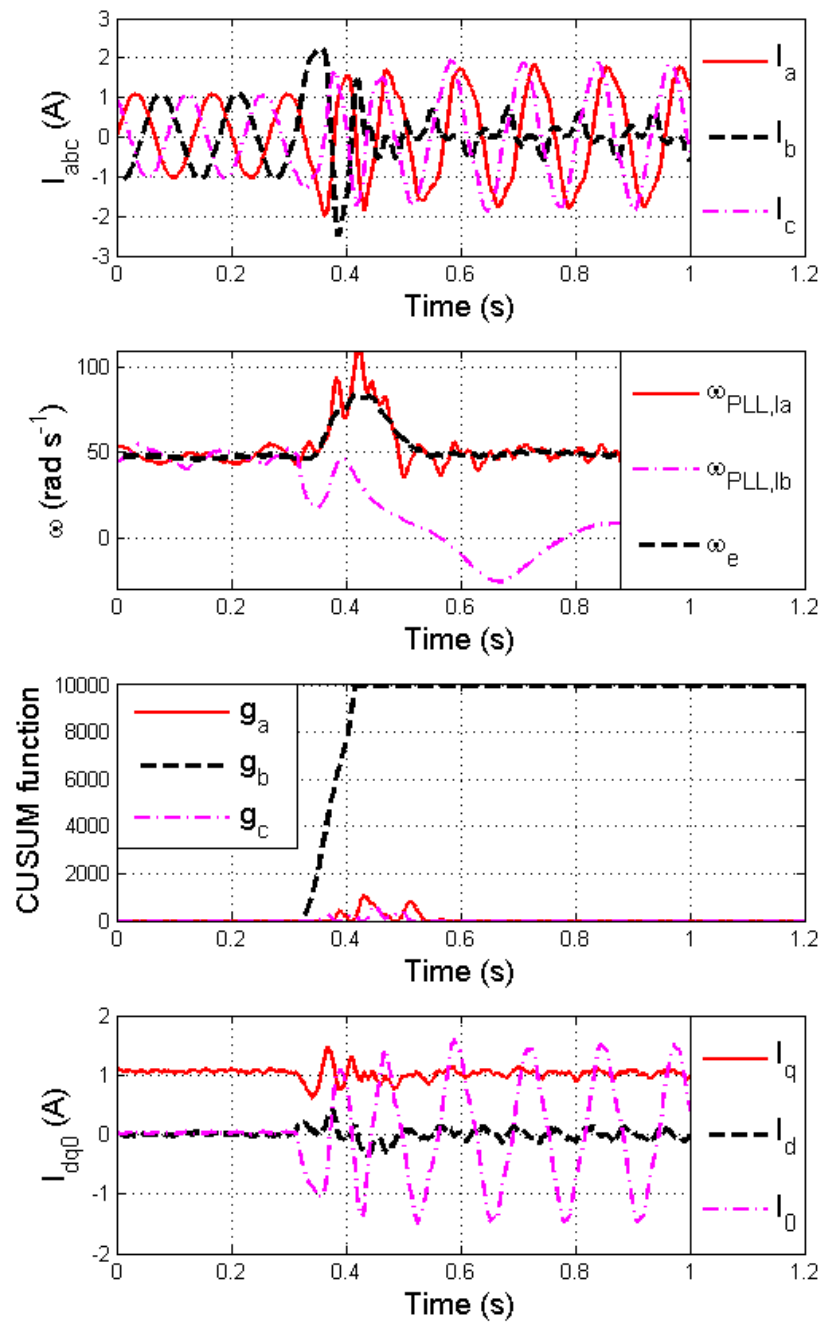

Figure 11. Response of the drive in case of current sensor fault ( $b$-phase). Fault is detected, isolated and the control is reconfigured when the $b$ CUSUM function reaches the threshold.

\section{CONCLUSION}

A PLL-based software fault detection and isolation for single-phase open-circuit and current sensor faults has been presented and validated with experimental results. The fault diagnosis is used to reconfigure the control by taking advantage of the fault-tolerant topology. A systematic decision to stop supplying the faulty phase has been adopted.

\section{ACKNOWLEDGMENT}

Fabien Meinguet would like to thank the Belgian Fund for training in Research in Industry and in Agriculture (F.R.I.A.) for the financing of this research project.

\section{REFERENCES}

[1] P. Wikstrom, L.A. Terens and H. Kobi, "Reliability, availability, and maintainability of high-power variable-speed drive systems", IEEE Trans. on Industry Applications, Vol. 36, No. 1, pp: 231-241, January/February 2000.

[2] B.C. Mecrow, D.J. Atkinson, A.G. Jack, S. Green, J.A. Haylock and J. Coles, "The need for fault tolerance in an aeroengine electric fuel control system", IEE Colloquium on Electrical Machines and Systems for the More Electric Aircraft, Ref. No. 1999/180, pp: 9/1-9/5, 1999.
[3] S. Nandi, H. Toliyat and X. Li, "Condition monitoring and fault diagnosis of electrical motors - a review", IEEE Trans. on Energy Conversion, Vol. 20, No. 4, pp: 719-729, December 2005.

[4] M. El Hachemi Benbouzid, "A review of induction motors signature analysis as a medium for faults detection", IEEE Trans. on Industrial Electronics, Vol. 47, No.5, pp: 984-993, October 2000.

[5] A. Bellini, F. Filippetti, C. Tassoni, and G.-A. Capolino, "Advances in diagnostic techniques for induction machines", IEEE Trans. on Industrial Electronics, Vol. 55, No. 12, pp: 4109- 4126, December 2008.

[6] B. Welchko, T. Lipo, T. Jahns, S. Schulz, "Fault tolerant three-phase AC motor drive topologies: a comparison of features, cost and limitations", IEEE Trans. on Power Electronics, Vol. 19, No. 4, pp: 539-546, July 2004.

[7] F. Meinguet, E. Semail and J. Gyselinck, "Enhanced control of a PMSM supplied by a four-leg voltage source inverter using the homopolar torque", Proc. of the International Conference on Electrical Machines (ICEM), CD-ROM, 2008.

[8] N. Bianchi, S. Bolognani, M. Dai Pré and G. Grezzani, "Design considerations for fractional-slot winding configurations of synchronous machines, IEEE Trans. on Industry Applications, Vol. 42, No. 4, pp: 997-1006, July/August 2006.

[9] Y.-S. Jeong, S.-K. Sul, S.E. Schulz and N.R. Patel, "Fault detection and fault-tolerant control of interior permanent-magnet motor drive system for electric vehicle", IEEE Trans. on Industry Applications, Vol. 41, No. 1, pp: 46-51, January/February 2005.

[10] K. Rothenhagen and F. Fuchs, "Current Sensor Fault Detection, Isolation, and Reconfiguration for Doubly Fed Induction Generators", IEEE Trans. on Industrial Electronics, Vol. 56, No. 10, pp: 4239-4245, Octobre 2009.

[11] M. Gàlvez-Carrillo and M. Kinnaert, "Sensor fault detection and isolation in three-phase systems using a signal-based approach", IET Control Theory \& Application, Vol. 4, No. 9, pp: 1838-1848, September 2010.

[12] F. Meinguet and J. Gyselinck, "Sensor and open-phase fault detection and isolation for three-phase AC drives", Proc. of the Power Electronics, Machines and Drives conference (PEMD), April 2010.

[13] F. Meinguet, E. Semail, J. Gyselinck, "An on-line method for stator fault detection in multi-phase PMSM drives", Proc. of the IEEE Vehicle Power and Propulsion Conference (VPPC), September 2010.

[14] D. Diallo, M. Benbouzid and A. Makouf, "A fault-tolerant control architecture for induction motor drives in automotive applications", IEEE Trans. on Vehicular Technology, Vol. 53, No. 6, pp: 1847-1855, November 2004.

[15] F. Meinguet, J. Gyselinck, "Control strategies and reconfiguration of four-leg inverter PMSM drives in case of single-phase open-circuit faults", Proc. of the IEEE International Electric Machines and Drives Conference (IEMDC), paper ID 11117, May 2009.

[16] S. Bolognani, M. Zordan and M. Zigliotto, "Experimental fault-tolerant control of a PMSM drive", IEEE Trans. on Industrial Electronics, Vol. 47, No. 5, pp: 1134-1141, October 2000.

[17] S.K. Chung, "A phase tracking system for three phase utility interface inverters", IEEE Trans. on Power Electronics, Vol. 15, No. 3, pp: 431438, May 2000.

[18] M. Blanke, M. Kinnaert, J. Lunze and M. Staroswiecki, "Diagnosis and fault-tolerant control", Springer, Second Edition, Chapter 6, pp: 238-263, 2006.

[19] P. Rodriguez, R. Teodorescu, I. Candela, A.V. Timbus, M. Liserre, F. Blaabjerg, "New positive-sequence voltage detector for grid synchronization of power converters under faulty grid conditions", Power Electronics Specialists Conference (PESC), June 2006.

[20] R. Zhang, V. Himamshu Prasad, D. Boroyevich and F. C. Lee,"Threedimensional space vector modulation for four-leg voltage-source converters", IEEE Trans. on Power Electronics, Vol. 17, No. 3, pp: 314-326, May 2002.

[21] J.-H. Kim and S.-K. Sul, "A carrier-based PWM method for three-phase four-leg voltage source converters", IEEE Trans. on Power Electronics, Vol. 19, No. 1, pp: 66-75, January 2004.

[22] B.A. Welchko, T.M. Jahns and S. Hiti, "IPM synchronous machine drive response to a singlephase open circuit fault", IEEE Trans. on Power Electronics, Vol. 17, No. 5, pp: 764-771, September 2002. 